\title{
A Fresh Look at the Relationship between TSH and Free Thyroxine in Cross-Sectional Data
}

\author{
Linde A.C. De Grande Katleen Van Uytfanghe Linda M. Thienpont \\ Laboratory for Analytical Chemistry, Faculty of Pharmaceutical Sciences, Ghent University, Ghent, Belgium
}

Dear Editor,

The classical log-linear relationship between thyroid-stimulating hormone (TSH) and free thyroxine $\left(\mathrm{FT}_{4}\right)$ generally reflects on the reasonable correlation between both hormones, while particularly emphasizing that small changes in $\mathrm{FT}_{4}$ are accompanied by larger changes in TSH [1]. Recently, refining this relationship in cross-sectional data has received new interest [2-4]. Different from the classical monotonous relationship over the whole thyroid function range, the referred authors propose three different relationships in the hypo-, eu-, and hyperthyroid range. While they use different mathematical models to describe the relationships, they have in common that they work with functions that interconnect at the transition from the hypo-/ euthyroid and eu-/hyperthyroid states. Although the real clinical relevance of knowing the exact mathematical relationship may be debated, it cannot be denied that the relation between $\mathrm{TSH}$ and $\mathrm{FT}_{4}$ is discussed in view of more precisely defining the subclinical state of thyroid dysfunction, and/or even brought up by some scientists as evaluation criterion for the validity of a $\mathrm{FT}_{4}$ assay $[2,5]$.

Here we take a fresh look at the TSH/ $\mathrm{FT}_{4}$ relationship, based on previously described data [1]. They were from 8,152 unselected patients (median age: 61 years, range: 18-100) from the Department of Endocrinology or Nuclear Medicine of the Klinikum Lüdenscheid in Germany, who presented with various thyroid disorders. Data from pregnant women and patients with pituitary or hypothalamic disorders were excluded, as well as from patients with conditions that potentially interfere with thyroid testing. Note that corresponding to the limits of the Abbott enzyme immunoassay, which was used for measuring both
TSH and $\mathrm{FT}_{4}$, the TSH data are truncated at 0.001 and $100 \mathrm{mIU} / \mathrm{l}$, respectively. Regression and correlation results were calculated by Microsoft Excel 2010.

Different from current practice, we plotted $\log \mathrm{TSH}$ on the $\mathrm{x}$-axis and $\mathrm{FT}_{4}$ on

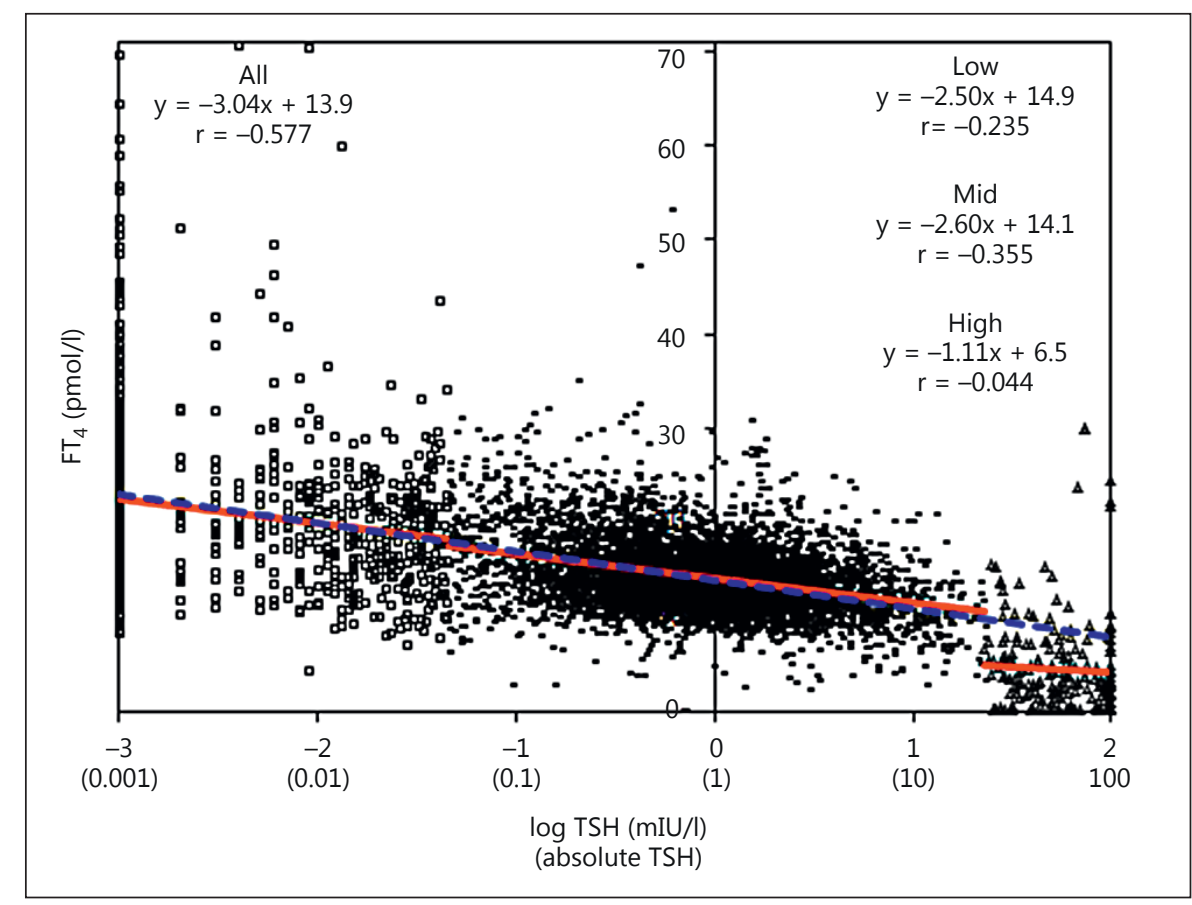

Fig. 1. $\log \mathrm{TSH}$ is plotted on the $\mathrm{x}$-axis and $\mathrm{FT}_{4}$ on the $\mathrm{y}$-axis. This reveals three clusters depending on the TSH-concentration: $\square$ : 'low', -: 'mid', and $\Delta$ : 'high'. The blue line is the linear regression line for the complete concentration range; the red lines are the linear regression lines for the different clusters. A clear break with little correlation in the TSH/ $\mathrm{FT}_{4}$ relationship for the 'high'-trophic hormone data group can be seen.

\begin{tabular}{ll}
\hline KARGER 125/\% & $\begin{array}{l}\text { ( 2015 European Thyroid Association } \\
\text { Published by S. Karger AG, Basel } \\
2235-0640 / 15 / 0041-0069 \$ 39.50 / 0\end{array}$ \\
$\begin{array}{l}\text { E-Mail karger@karger.com } \\
\text { www.karger.com/etj }\end{array}$ &
\end{tabular}

www.karger.com/etj
Linda M. Thienpont

Laboratory for Analytical Chemistry

Faculty of Pharmaceutical Sciences, Ghent University

Ottergemsesteenweg 460, BE-9000 Ghent (Belgium)

E-Mail linda.thienpont@ugent.be 
the y-axis (fig. 1). We did not define upfront the different concentration categories because we preferred to inspect the correlation of the complete dataset without any prejudice. Visual inspection of the plot reveals three clusters of TSH values from 0.001 to $<0.045 \mathrm{mIU} / 1$ ('low'), 0.045 to $<23$ $\mathrm{mIU} / \mathrm{l}$ ('mid'), and 23 to $100 \mathrm{mIU} / \mathrm{l}$ ('high'). Instead of a continuum, a clear break in the $\mathrm{TSH} / \mathrm{FT}_{4}$ relationship for the high-TSH data group can be seen. This is also reflected in the partial regression equations $(\mathrm{y}=$ $-2.50 \mathrm{x}+14.9$, 'low'; $\mathrm{y}=-2.60 \mathrm{x}+14.1$, 'mid'; $y=-1.11 \mathrm{x}+6.5$, 'high'). The regression equation over the whole range $(\mathrm{y}=$ $-3.04 \mathrm{x}+13.9$, 'all') is similar to the lowand mid-range data. The correlation data, in our opinion, are misleading and are mainly influenced by the TSH range (note: correlation over the whole range is $\mathrm{r}=$ -0.577 , while it is $r=-0.044$ in the high range). Although the precision and accu- racy of the $\mathrm{FT}_{4}$ measurement results in the low concentration range might be jeopardized by the limit of quantitation of the used assay, we consider that the effect of increased random error would result in a higher scatter around the line representing the $\mathrm{TSH} / \mathrm{FT}_{4}$ relationship, though without affecting the regression coefficients. Regarding the inaccuracy of measurement, we know from a previous study that most $\mathrm{FT}_{4}$ assays tend to have a positive calibration bias in the low concentration range versus a significantly negative one in the mid- to high-concentration range [6]. This allows us to infer that after correction of this bias, the break in the $\mathrm{TSH} / \mathrm{FT}_{4}$ relationship would become even more obvious.

Our 'fresh' presentation of TSH/FT data suggests that the log-linear relationship between both hormones holds also in cross-sectional data up to TSH concentra- tions of $\sim 23 \mathrm{mIU} / \mathrm{l}\left(\mathrm{FT}_{4}\right.$ of $\sim 10 \mathrm{pmol} / \mathrm{l}$; note: the actual values will depend on the assays used). However, from this concentration on, there is a clear 'break' in the relationship with little correlation between $\mathrm{TSH}$ and $\mathrm{FT}_{4}$. Consequently, curve fittings for the $\mathrm{TSH} / \mathrm{FT}_{4}$ relationship in both ranges should not be interconnected.

\section{Acknowledgments}

We thank Professors Rudolf Hoermann and Rolf Larisch (Klinikum Lüdenscheid) for the provision of the raw data. We thank Dr. Dietmar Stöckl (STT Consulting) for helpful discussions and advice in statistics.

\section{Disclosure Statement}

The authors have nothing to disclose.

\section{References}

1 Demers LM, Spencer CA: Laboratory Medicine Practice Guidelines: Laboratory Support for the Diagnosis and Monitoring of Thyroid Disease. Washington, National Academy of Clinical Biochemistry (NACB), 2002.

-2 Hoermann R, Eckl W, Hoermann C, Larisch $\mathrm{R}$ : Complex relationship between free thyroxine and TSH in the regulation of thyroid function. Eur J Endocrinol 2010;162:1123-1129.

3 Clark PM, Holder RL, Haque SM, Hobbs FD, Roberts LM, Franklyn JA: The relationship between serum TSH and free $\mathrm{T}_{4}$ in older people. J Clin Pathol 2012;65:463-465.

$\checkmark 4$ Hadlow NC, Rothacker KM, Wardrop R, Brown SJ, Lim EM, Walsh JP: The relationship between $\mathrm{TSH}$ and free $\mathrm{T}_{4}$ in a large population is complex and nonlinear and differs by age and sex. J Clin Endocrinol Metab 2013;98: 2936-2943.

5 Jonklaas J, Kahric-Janicic N, Soldin OP, Soldin SJ: Correlations of free thyroid hormones measured by tandem mass spectrom- etry and immunoassay with thyroid-stimulating hormone across 4 patient populations. Clin Chem 2009;55:1380-1388.

6 Thienpont LM, Van Uytfanghe K, Van Houcke S, Das B, Faix JD, MacKenzie F, Quinn FA, Rottmann M, Van den Bruel A; IFCC Committee for Standardization of Thyroid Function Tests (C-STFT): A progress report of the IFCC Committee for standardization of thyroid function tests. Eur Thyroid J 2014;3:109-116. 